\title{
Anal Canal Adenocarcinoma
}

National Cancer Institute

\section{Source}

National Cancer Institute. Anal Canal Adenocarcinoma. NCI Thesaurus. Code C7471.

An anal adenocarcinoma arising from the anal canal mucosa. Morphologically, it resembles the adenocarcinoma which arises from the colorectal glandular epithelium.

Symptoms include anal pruritus, discomfort when sitting, pain, change in bowel habit, and bleeding. 